\title{
EXPERIMENTAL STUDY ON BLACK COTTON SOIL STABILIZED USING SOILTECH MK III POL YMER
}

\author{
J.Ranjitha ${ }^{1}$, Supritha D.K ${ }^{2}$, Hitaishi.P ${ }^{3}$, Pratik Kumar ${ }^{4}$ \\ ${ }^{1}$ Assistant Professor, Department of Civil Engineering, DSCE, Bengaluru, Karnataka, India \\ ${ }^{2}$ Assistant Professor, Department of Civil Engineering, DSCE, Bengaluru, Karnataka, India \\ ${ }^{3} U G$ Student, Department of Civil Engineering DSCE, Bengaluru, Karnataka, India \\ ${ }^{4} U G$ Student, Department of Civil Engineering DSCE, Bengaluru, Karnataka, India
}

\begin{abstract}
Road infrastructure in India is developing at a very fast rate. A good pavement provides safe, comfortable and economical movement of traffic. The road thickness depends on various geotechnical properties of subgrade soil and traffic intensity. The pavement construction is becoming costlier because of very high cost of construction materials and transportation cost of such materials from long distances. The growing concern over environmental degradation due to borrowing of large quantity of soil and aggregates for construction of pavement has made the search for new techniques of stabilization. The subgrade soil should have high Maximum dry density (MDD) and low Optimum moisture content (OMC) so that it can take up the load of the overlying layers and the traffic. The high MDD and corresponding OMC can be achieved by stabilizing the soil using suitable stabilizer. In the present work the effect of using Nano Polymer called SoilTech MK III as a stabilizer to improve the properties of Black Cotton soil collected from Ranibennur region, Karnataka, India were determined. The laboratory experiments were conducted on the samples of BC soil and BC soil with stabilizer for Compaction test, UCS (Unconfined Compression Strength) and CBR (California Bearing Ratio) tests. Various samples were prepared by taking soil with different percentage of SoilTech MK III Polymer (0.2\%, 0.4\%, 0.6\%, 0.8\% and 1.0\%). The comparison of the results with and without the use of SoilTech MK III has been done. All test were conducted as per IS 2720 standards.
\end{abstract}

Keywords: Subgrade, Black Cotton Soil, SoilTech MK III Polymer, CBR Test.

\section{INTRODUCTION}

\subsection{General introduction to the work}

Roads, both urban and rural, require soils with good engineering properties. However, in the construction work the problem arises, when the soils with unsuitable engineering properties are encountered and hence it is necessary to improve the geotechnical properties of the soils to make them acceptable for construction. In any highway construction, taking economy into consideration the earthwork constitutes of approximately about $30 \%$ of the complete cost of the whole project. Hence, the preparation of subgrade is an important activity in highway construction. The pavement is directly laid over the prepared subgrade which bears the load of the over lying layers and the traffic load over the pavement. Thus, the adequate design of subgrade plays a vital role in the successful performance of the pavement.

Black cotton soil is an organic clay of medium-high compressibility and constitutes as a major soil group in India. These soils are mainly characterized by high swelling and shrinkage properties. Black cotton (BC) soil covers about $25 \%$ of the total area of India and mainly occurs in central part and western part of India. Because of its high shrinkage and swelling properties, the BC soil has been a huge challenge to the highway engineers. In dry condition, $\mathrm{BC}$ is hard but loses its strength in wet condition. Due to alternate wetting-drying process vertical movement occurs in the soil mass, these vertical movement further develops and leads to pavement failure in the form of settlement, heavy depression, cracking etc.

The term soil stabilization refers to altering the physical properties of soil which improves the stability and bearing capacity of the soil, so that it can take up the loads of overlying layers and the traffic. This can be achieved by stabilizing the soil using suitable modifiers which modifies the geotechnical properties of the soil and imparts strength. Sometimes chemical binders are used to enhance the bearing capacity of the soil. These chemical binders range from waste products to manufactured materials. These chemical additives bind the soil particles to make the soil more cohesive and water resistant. Soil binders has two functions, erosion control and soil stabilization. The success of soil binders depends on various criteria like local conditions, type of soil, use of stabilized soil etc. The stabilizer used for stabilizing the soil should be environmentally friendly, less hazardous etc.

\subsection{Objectives of the present work}

(i) The important objective is to determine the optimum dosage of SoilTech MK III polymer required to stabilize the black cotton soil of the selected location. 
(ii) To study the basic geotechnical properties of natural and treated soil.

(iii) To determine the strength obtained after stabilizing the black cotton using SoilTech MK III.

(iv) To ascertain the alterations in the strength parameters of treated and natural soil specimen by California Bearing Ratio test (CBR) with $0.2 \% 0.4 \% 0.6 \% 0.8 \%$ and $1 \%$ varied dosages of SoilTech MK III polymer.

(v) To evaluate the changes in Unconfined Compressive strength (UCS) with $0.2 \% 0.4 \% 0.6 \% 0.8 \%$ and $1 \%$ varied dosages of SoilTech MK III polymer.

\subsection{Literature Review}

B M Lekha et $\mathrm{al}^{(5)}$ investigated the behaviour of both treated and untreated black cotton soil. The soil was procured from the Mangalore region. The nano-chemical called TerraSil was used as a stabilizer. They carried out the various tests like liquid limit, plastic limit, proctor compaction, UCS and CBR by curing it for periods of 7, 14 and 28 days. It was then found that the use of TerraSil as a stabilizer significantly increased the strength of the soil and also imparted impermeability along with the strength.

C.E.G.Justo and Krishnamurthy ${ }^{(6)}$ have conducted a study on laboratory studies on properties of $\mathrm{BC}$ soil treated with RBI- 81 stabiliser. It was found that the soil which was stabilized with RBI-81 did not show significant variations in the values of liquid limit. But there was a significant increase in the plastic limit values which in term resulted in reduction of Plasticity-Index (PI). The PI values decreased from $32 \%$ to $38 \%$ when $6 \%$ of RBI- 81 stabilizer was added to the soil. A slight variation in both MDD and OMC was also observed. The soaked CBR value of the soil which was stabilized at $4 \%$ of RBI-81 showed significant increment after 7 days of curing.

\section{MATERIALS AND METHODOLOGY}

\subsection{Black Cotton Soil}

For the present work, black cotton soil was procured from Ranibennur Taluk of Haveri District, Karnataka. The soil was borrowed from a depth of $1 \mathrm{~m}$ from the ground level. The soil was then dried and manually pulverized. All the tests were done as per IS-2720.

\subsection{SoilTech MK III Polymer}

SoilTech MK III is the third generation soil stabilising polymer and dust suppressant. This product achieves the strength from mechanical compaction. It is dark brown in colour. It possesses medium viscosity and has an ability to dissolve in water without leaving any residue and precipitation.

The physical and chemical properties of SoilTech MK III polymer obtained from Kaveri Ultra Polymer Pvt.Ltd is given in Table-1.
Table -1: Physical and Chemical properties of SoilTech MK III polymer

\begin{tabular}{|l|l|l|}
\hline $\begin{array}{l}\text { SI } \\
\text { No }\end{array}$ & Property & Description \\
\hline 1 & Appearance & Dark Brown/Black Liquid \\
\hline 2 & Odour & Slight \\
\hline 3 & pH & $8.0-9.0$ \\
\hline 4 & Boiling Point & $\begin{array}{l}\text { Approximately } 100^{\circ}(\text { as per } \\
\text { water })\end{array}$ \\
\hline 5 & Flammability & N/A \\
\hline 6 & Vapour Pressure & As per water \\
\hline 7 & Specific Gravity & $>1.0$ \\
\hline 8 & Water Solubility & Fully miscible \\
\hline
\end{tabular}

\subsection{Preparation of polymer stabilized soil sample}

In the present study, compaction test is conducted on varying percentages $0.2 \%, 0.4 \%, 0.6 \%, 0.8 \%$ and $1.0 \%$ of SoilTech MK III Polymer to estimate the optimum dosage. The obtained optimum dosage is then added to the water (OMC). For example; to prepare the SoilTech MK III solution for $0.4 \%, 4 \mathrm{ml}$ of SoilTech MK III Polymer is added to one litre of water and mixed thoroughly. After preparing the SoilTech MK III solution this solution added to the weighed quantity of soil and mixed thoroughly.

\subsection{Curing of stabilized specimen}

The polymer stabilized soil specimens were prepared for conducting CBR and Unconfined Compression (UCC) test. The prepared specimens were then cured by drying for a period of 4 or 7 days. After the curing period, the specimens were tested. The CBR specimen is then kept under soaked condition for 4 days.

Polymer is cured by way of loss of moisture in the sample. The concept is similar to that of reverse osmosis where moisture escapes from inside the sample into the atmosphere but prevents water from penetrating.

\subsection{Experimental Methodology}

Fig. 1 indicates the methodology adopted in carrying out the various tests for the study. 


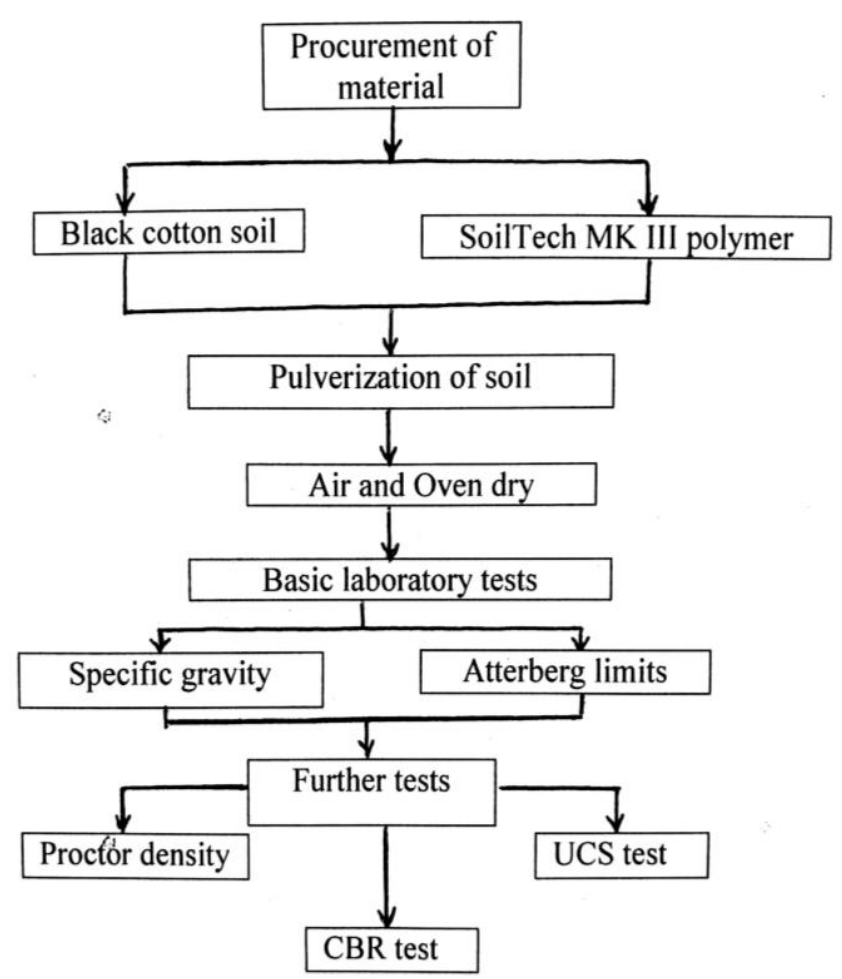

Fig -1: Layout plan of the experiments carried out

\section{RESULTS}

\subsection{Black Cotton Soil Properties}

The basic properties of the normal black cotton soil are summarized in Table -2 .

Table -2: Geotechnical properties of Black cotton soil

\begin{tabular}{|l|c|}
\hline \multicolumn{1}{|c|}{ Property } & Description \\
\hline Colour of the soil & Dark Grey \\
\hline Percentage passing $75 \mu$ sieve & $78.90 \%$ \\
\hline Liquid Limit & 61.2 \\
\hline Plastic Limit & 31.4 \\
\hline Plasticity Index & 29.8 \\
\hline Shrinkage Limit & 15.15 \\
\hline HRB Classification & $\mathrm{A}-7 \mathrm{a}$ \\
\hline $\begin{array}{l}\text { Unified Soil Classification System } \\
\text { (USCS) }\end{array}$ & $\mathrm{CH}$ \\
\hline Specific Gravity & 2.7 \\
\hline Maxium Dry Density & $1560 \mathrm{~kg} / \mathrm{m}^{3}$ \\
\hline Optimum Moisture Content & 28.5 \\
\hline Unconfined Compression Strength(UCS) & 75.8 \\
\hline California Bearing Ratio(CBR) & $24.40 \%$ \\
\hline Unsoaked & 2.47 \\
\hline Soaked & 1.58 \\
\hline Natural Moisture Content & \multicolumn{2}{|c|}{} \\
\hline & \\
\hline
\end{tabular}

\subsection{Liquid Limit Test}

The liquid limit test was conducted on soil treated with varying proportion of polymer. The results are given in Table-3.

Table -3: Liquid limit values of soil treated with polymer

\begin{tabular}{|c|c|c|c|c|c|c|}
\hline बि & 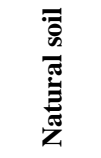 & 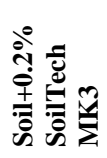 & 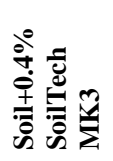 & 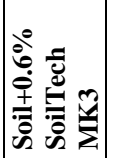 & 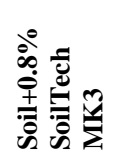 & 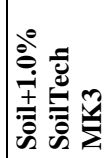 \\
\hline $\begin{array}{l}\text { Liquid } \\
\text { Limit }\end{array}$ & $61.20 \%$ & $52.80 \%$ & $50.40 \%$ & $52 \%$ & $53.20 \%$ & $55 \%$ \\
\hline
\end{tabular}

\subsection{Plastic limit test}

The plastic limit test was conducted on soil treated with varying proportion of polymer. The results are given in Table-4.

Table -4: Plastic limit values of soil treated with polymer

\begin{tabular}{|c|c|c|c|c|c|c|}
\hline 网 & 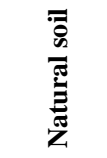 & 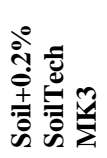 & 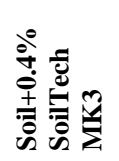 & 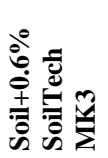 & 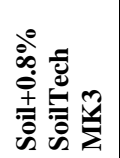 & 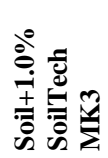 \\
\hline $\begin{array}{l}\text { Plastic } \\
\text { limit }\end{array}$ & $31.40 \%$ & $25.10 \%$ & $24.3 \% 2$ & $24.90 \%$ & $25.70 \%$ & $26.10 \%$ \\
\hline
\end{tabular}

\subsection{Plasticity Index}

The plasticity index value for soil treated with polymer is tabulated in Table-5.

Table-5:Plasticity index values of soil treated with polymer

\begin{tabular}{|c|c|c|c|c|c|c|}
\hline 育 & 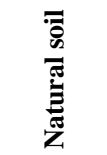 & 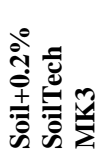 & 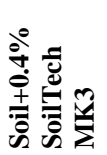 & 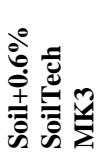 & 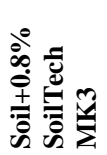 & 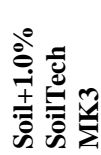 \\
\hline $\begin{array}{l}\text { Plasticity } \\
\text { Index }\end{array}$ & $29.80 \%$ & $27.70 \%$ & $26.10 \%$ & $27.10 \%$ & $28.30 \%$ & $28.90 \%$ \\
\hline
\end{tabular}

\subsection{Shrinkage Limit}

The results of the shrinkage limit tests are given in Table-6.

Table-6:Shrinkage limit values of soil treated with polymer

\begin{tabular}{|c|c|c|c|c|c|c|}
\hline 童 & 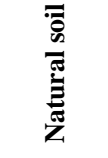 & 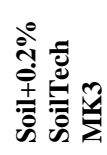 & 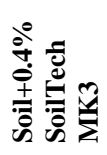 & 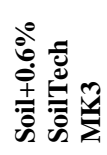 & 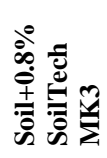 & 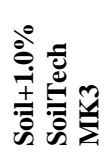 \\
\hline $\begin{array}{l}\text { Shrinkage } \\
\text { Limit }\end{array}$ & $15.15 \%$ & $12.60 \%$ & $11.20 \%$ & $12.00 \%$ & $13.10 \%$ & $14.00 \%$ \\
\hline
\end{tabular}

\subsection{Specific Gravity}

The results of the specific gravity test result values are given in Table-7. 
Table-7:Specific gravity values of soil treated with polymer

\begin{tabular}{|c|c|c|c|c|c|c|}
\hline 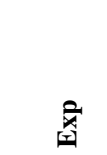 & 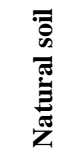 & 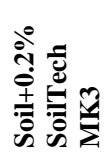 & 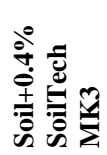 & 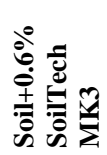 & 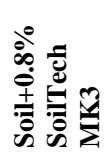 & 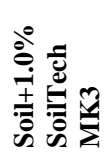 \\
\hline $\begin{array}{l}\text { Specific } \\
\text { Gravity }\end{array}$ & 2.7 & 2.5 & 2.39 & 2.44 & 2.49 & 2.55 \\
\hline
\end{tabular}

\subsection{Compaction Test}

Standard compaction test was carried out to determine maximum dry density(MDD) and the optimum moisture content(OMC) of the treated soil. The results are represented in graphical form in Fig-2 and Fig-3.

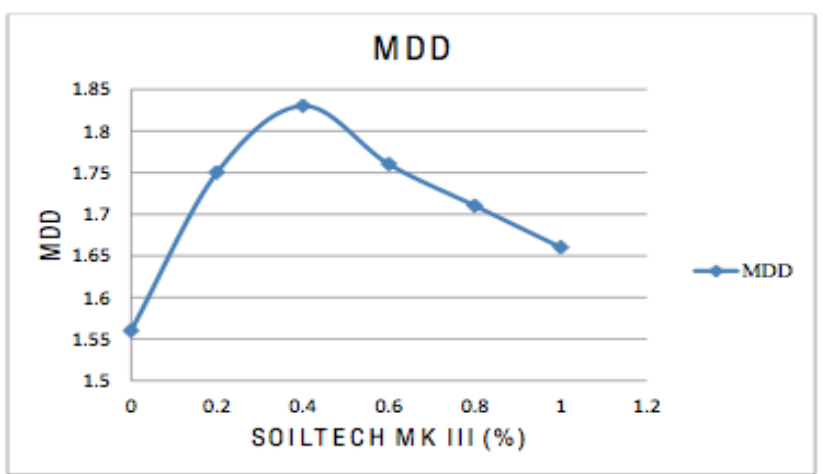

Fig -2: Variation in MDD with use of polymer

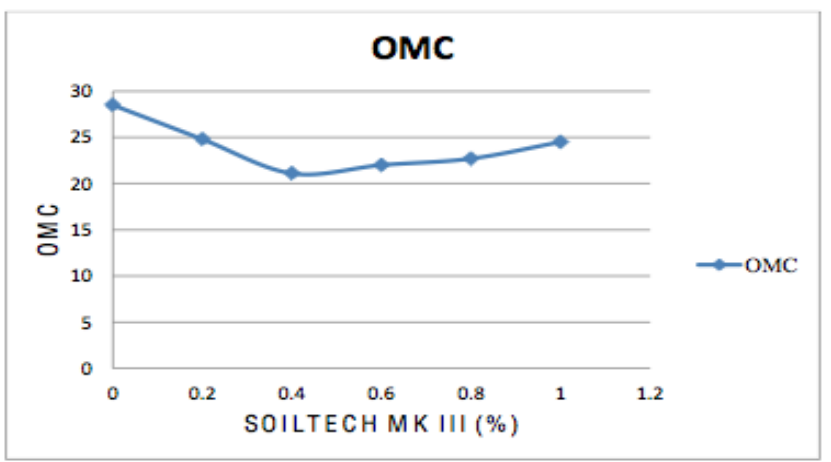

Fig -3: Variation in OMC with use of polymer

\subsection{Unconfined Compression Strength Test}

The results of unconfined compression strength (UCS) test is given in Fig-4.

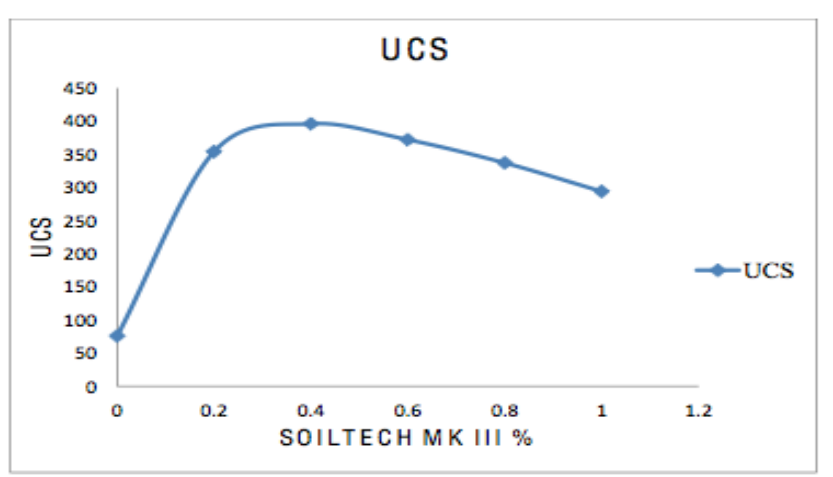

Fig -4: Variation in UCS with use of polymer

\subsection{California Bearing Ratio Test}

CBR tests were conducted on soil treated with varying percentages of polymer. The results obtained is shown in Fig-5.

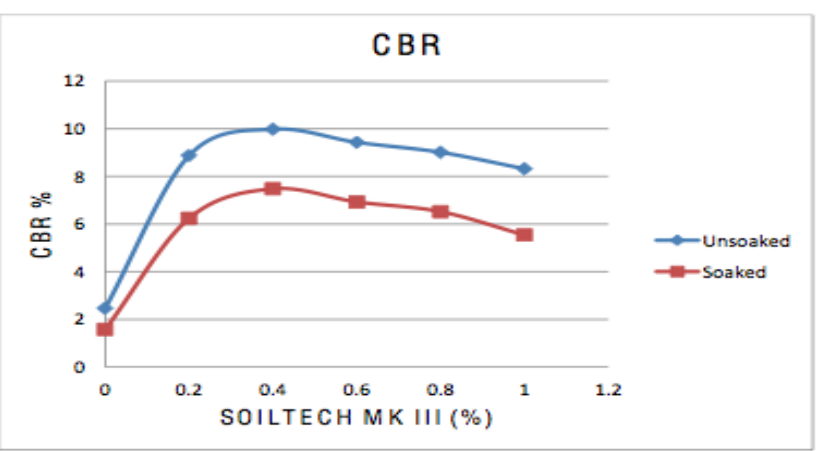

Fig -5: CBR of soil with use of polymer

\section{CONCLUSIONS}

(i) The basic laboratory tests conducted on black cotton soil shows that the soil has low strength and high volume changing property. The soil was classified under A- 7a subgroup of the HRB classification system. The high liquid limit of $61.2 \%$ and plasticity index of $29.8 \%$ concludes that the soil is clayey soil with high plasticity.

(ii) After stabilizing the soil with varying percentages of SoilTech MK III polymer, there is a considerable decrease in the liquid limit from $61.2 \%$ to $50.4 \%$ and plasticity index from $29.8 \%$ to $26.1 \%$.

(iii) Addition of $0.4 \%$ of SoilTech MK III polymer improves the compaction parameters of the soil by decreasing the OMC and increasing the MDD of the soil.

(iv) The increase in UCS value corresponding to the increase in SoilTech MK III content was found to be effective at $0.4 \%$. UCS increased from $75.8 \mathrm{KN} / \mathrm{m}^{2}$ from $396 \mathrm{KN} / \mathrm{m}^{2}$ for addition of $0.4 \%$ of polymer. Hence the stability value of the soil increases due to increment in the compressive strength.

(v) There was a considerable change in the CBR value of the treated soil. CBR changes were significant at $0.4 \%$ of SoilTech MK III polymer after 4 days of soaking as it achieves the required strength recommended by IRC: $37-$ 2001. CBR increases from $2.47 \%$ to $9.98 \%$ for unsoaked condition and from $1.58 \%$ to $7.48 \%$ for soaked condition at $0.4 \%$ of SoilTech MK III. This shows that there is an increase in the strength of the soil when stabilized with SoilTech MK III polymer.

\section{REFERENCES}

[1]. Abdul Jawad, S. N. (1991). "Characteristics and Chemical Treatment of Expansive Clay in Al-Qatif, Saudi Arabia." Enginering Geology, 32(3), 144-159.

[2]. Ajayi-Mejebi., Grisom,W.A., Smmith, L. S., and Johnes, E. E. (1991). "Epoxy- Resin-Based Chemical Stabilisation of a Fine, Poorly Graded Soil System." Transportation Research Record, (1296), 94-107.

[3]. Bary, P. V., Scott, D. E., Turco, R. F., and Badford, J. M. (1991). "Organic Polymers effect on Soil Shear Strength 
and Detachment by Single Rain-drops." Soil Science Society of America Journal, 54(2), 798-805.

[4]. Bolaander, P. (1999). "Laboratory Testing of Nontraditional Additives for Stabilisation of Roads and Trail Surfaces." Transportation Research Record, 2(1653), 25-32. [5]. B M Lekha, S Goutham, A U Ravi Shankar (2013), "Laboratory investigation of soil stabilized with Nano chemical", Proceedings of Geotechnical Conference, Roorkee.

[6]. C.E.G.Justo, Krishnamurthy (2008), "Laboratory studies on properties of soils treated with RBI-81stabilizer", RASTA Center for Road Technology.

[7]. IRC: 37-2001, "Guidelines for the design of flexible pavements", Indian road congress, New Delhi.

[8]. IS-2720(Part 1) (1983), "Preparation of Dry Soil sample for various tests", Indian standard institutions, New Delhi.

[9]. IS-2720(Part 5)(1985) - Method of test for soils, Determination of Liquid \& Plastic Limits, Indian standard institutions, New-Delhi.

[10]. IS-2720( Part 6 )(1972) - Determination of Shrinkage Factors, BIS, New Delhi

[11]. IS-2720(Part 3)(1980) - Determination of specific gravity, BIS, New Delhi

[12]. IS-2720(Part 7)(1980) - Determination Of moisture Content and Dry Density Relation Using Light Compaction test, BIS, New-Delhi.

[13]. IS-2720(Part 4)(1985) - Grain size analysis, Bureau of Indian Standards, New Delhi.

[14]. IS-2720(Part 10)(1991) - Determination of Unconfined

Compressive Strength (UCS), BIS, New-Delhi.

[15]. IS-2720(Part 16)(1987) - Determination of California Bearing Ratio (CBR), BIS, New-Delhi.

\section{BIOGRAPHIES}

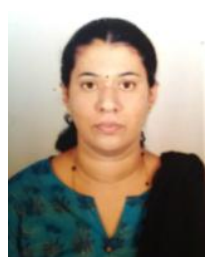

Mrs. J. Ranjitha

Asst. Prof., Dept. of Civil Engg.,

Dayananda Sagar College of Engineering,

Bengaluru-560078

Email Id:

ranjitha-cvl@dayanandasagar.edu

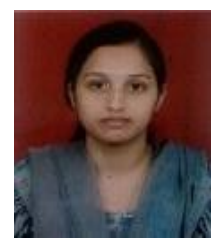

Mrs. Supritha D K

Asst. Prof., Dept. of Civil Engg.,

Dayananda Sagar College of Engineering,

Bengaluru-560078

Email Id: suprithagrantha@gmail.com

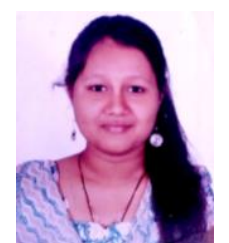

\section{Ms. Hitaishi. P}

3rd year B.E. Student, Dept. of Civil Engg., Dayananda Sagar College of Engineering,

Bengaluru- 560078

Email Id: hitaishipnaidu@gmail.co

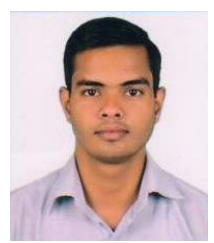

\section{Mr. Pratik Kumar}

3rd year B.E. Student, Dept. of Civil

Engg.,

Dayananda Sagar College of Engineering,

Bengaluru-560078

Email Id: 4703pratik@gmail.com 